\title{
Quality of life and sleep in obese adolescents
}

\author{
Qualidade de vida e do sono de adolescentes obesos \\ Giovina Turco', Tatiana Bobbio², Rubens Reimão ${ }^{3}$, Sueli Rossini ${ }^{4}$, Helen Pereira ${ }^{5}$, Antonio Barros Filho ${ }^{6}$
}

\begin{abstract}
Obesity and sleep disorders in adolescence are strongly associated, and they impact both on the health and on quality of life (QL) in this age group. Objective: To comparatively assess QL and sleep in obese and eutrophic adolescents, who are older than ten years of age. Methods: Cross-sectional study including obese adolescents. This analysis was carried out between August 2009 and August 2010. The Control (eutrophic) Group comprised schoolchildren recruited from State schools in the city of Americana, in São Paulo State, Brazil. Instruments applied included a standardized questionnaire, the Sleep Behavior Questionnaire (SBQ), and the Pediatric QL Inventory (PedsQL TM 4.0). Results: The obese adolescents had poorer QL on physical ( $p<0.001)$, emotional ( $p=0.03)$, and social $(p=0.002)$ functioning domains. A difference in mean psychosocial functioning was found between the groups $(p=0.009)$ with obese subjects having a mean score of $69.5( \pm 16.0)$ and in eutrophic individuals of 76.2 $( \pm 16.7)$. A greater number of sleep problems was evident in the Obese Group ( $p=0.03$ ). Conclusions: The obese adolescents had an impaired $Q L$ and a higher frequency of sleep problems compared to the eutrophic subjects.
\end{abstract}

Key words: sleep, adolescents, obesity, quality of life.

RESUMO

Obesidade e distúrbios do sono na adolescência estão amplamente associados, afetando a saúde e a qualidade de vida (QV) de tal grupo etário. Objetivo: Foi avaliar comparando a QV e o sono em adolescentes obesos e eutróficos maiores de dez anos. Métodos: Estudo transversal realizado entre agosto de 2009 e agosto de 2010, com adolescentes obesos. O Grupo Controle (eutróficos) foi constituído por estudantes da rede pública de ensino da cidade de Americana, em São Paulo. Foram utilizados ficha de identificação, Questionário do Comportamento do Sono (SBQ), Questionário de QV (PedsQLTM 4.0) como instrumentos. Resultados: Os adolescentes obesos apresentaram QV inferior à dos controles nos domínios físico ( $p<0,001)$, emocional $(p=0,03)$ e social $(p=0,002)$. Houve diferença em relação à avaliação psicossocial entre obesos e eutróficos (médias de 69,5 $\pm 16,0$ e 76,2 $\pm 16,7$, respectivamente). 0 grupo de adolescentes obesos apresentou maior quantidade de distúrbios do sono ( $p=0,03)$. Conclusões: Adolescentes obesos apresentaram prejuízo na QV e maior quantidade de distúrbios do sono comparados aos indivíduos eutróficos.

Palavras-Chave: sono, adolescentes, obesidade, qualidade de vida.

Obesity is defined as excess body fat versus lean mass, and it is classified as a chronic noncommunicable disease. This condition is associated with a broad array of complications, including cardiovascular, endocrine-metabolic, and orthopedic issues as well as breathing, sleep, and psychological disorders, among others ${ }^{1}$. Psychosocial disorders related to obesity include anxiety, depression, anguish, low self-esteem, guilt feelings, social adjustment problems, and behavioral/conduct disorders. These disorders can constitute the cause or effect of the weight gain process and negatively impact on quality of life $(\mathrm{QL})^{2,3}$.

Studies have found that lack of physical activity, poor diet, high consumption of processed foods, low intake of fruit, vegetables and legumes as well as frequent computer, videogame and television use, are strongly associated with the development of obesity and reduced total sleep time ${ }^{4,5}$. An important theme underpinning these investigations centers on the relationship between sleep disorders and cultural and familial

Study carried out as part of the Postgraduate Program of the Center for Investigation in Pediatrics of the School of Medicine at the Universidade Estadual de Campinas (FCM-UNICAMP), Campinas SP, Brazil.

${ }^{1}$ Psychologist, Masters from the Center for Investigation in Pediatrics of the FCM-UNICAMP, Campinas SP, Brazil;

${ }^{2}$ Physical therapist, Postdoctorate, Professor at the Universidade do Estado de Santa Catarina (UDESC), Florianópolis SC, Brazil;

${ }^{3}$ Professor, Postdoctorate from the Division of Neurologic Medicine of the Clínicas Hospital of the Universidade de São Paulo (USP) School of Medicine; Head of the Group for Advanced Research in Sleep Medicine of the Clínicas Hospital of the USP School of Medicine, São Paulo SP, Brazil;

${ }^{4}$ Psychologist, PhD in Psychology, Researcher of the Division of Neurologic Medicine of the Clínicas Hospital of the USP School of Medicine, São Paulo SP, Brazil;

${ }^{5}$ Nutritionist, Masters from the Center for Investigation in Pediatrics of the FCM-UNICAMP, Campinas SP, Brazil;

${ }^{6}$ Professor, MD of the Department of Pediatrics of the FCM-UNICAMP, Campinas SP, Brazil.

Correspondence: Rubens Reimão;Avenida Indianópolis 2.784;04062-003 São Paulo SP - Brasil; E-mails: rubens.reimao@gmail.com; reimaorubensneuro@yahoo.com Conflict of interest: There is no conflict of interest to declare.

Received 18 November 2012; Received in final form 27 August 2012; Accepted 03 September 2012 
habits, which are potentially harmful to the healthy development of adolescents ${ }^{5,6}$.

Partial and chronic sleep losses can result in endocrine and metabolic alterations, which in turn increase hunger and appetite leading to higher food intake patterns. Individuals with this profile generally become reticent towards practicing physical activities, largely as a result of the fatigue caused by sleep deficit, further contributing to increased risk for overweight and obesity?

The syndrome of obstructive sleep apnea (OSA) is a prevalent sleep disorder associated with weight gain, obesity and type 2 diabetes, conditions that interact with each other. Obesity is a major risk factor for the OSA, with body mass index (BMI), visceral fat and neck circumference being important predictors of its clinical expression. Reduced overall performance in adolescents stems directly from this condition ${ }^{8,9}$.

Studies measuring QL have gained increasing research attention, yielding important health indicators and helping to direct public policies that reiterate the need of assessing treatment approaches and socioeducational measures to improve QL, based on patients' clinical QL and health status ${ }^{10}$.

Therefore, the aim of the present study was to assess quality of sleep and QL in obese adolescents.

\section{METHODS}

An observational, analytic, cross-sectional study comparing obese and nonobese adolescents was carried out.

The study involved a sample of 120 adolescents from both genders, older than 10 years of age, spanning from August 2009 to August 2010. The study group comprised 61 obese adolescents that were residents of the city and district of Campinas. The classification of participants' nutritional status was determined based on the percentile of BMI $\left(\mathrm{kg} / \mathrm{m}^{2}\right)$, using the World Health Organization Child Growth Standards as a reference ${ }^{11}$.

Inclusion criteria for the study group were: a BMI $\geq$ p95 (overweight for age and sex), age of 10 to 14 years; agreement and signature of the free informed consent by parents/guardians. The Control Group comprised 59 agematched eutrophic adolescents $(\mathrm{BMI}<\mathrm{p} 85)$, who were schoolchildren from State schools in the municipality of Americana, São Paulo State, in Brazil.

Individuals meeting the following criteria were excluded: those presenting any chronic diseases, cardiopathies, and physical or mental disabilities.

\section{Instruments}

A standardized questionnaire was applied to patients and controls in order to obtain demographic and clinical data, including educational level, sex, BMI, health problems, and medication use. Family socioeconomic level according to the
Brazilian Economic Classification Criteria $(\mathrm{ABEP})^{12}$ was also evaluated. In it, educational level of the household head was rated from zero to five points, which were also provided according to the durable consumer goods owned by the family (color television, radio, automobile, vacuum cleaner, washing machine, DVD player, refrigerator, and freezer) and number of bathrooms. The sum of these indicators was used to stratify individuals into classes ranging from $\mathrm{A} 1$ (from 30 to 34 points), the most well-off, to $\mathrm{E}$ ( from 0 to 5 points), the least well-off.

The Sleep Behavior Questionnaire $(\mathrm{SBQ})^{13}$ consists of a questionnaire collecting information on overall sleep behaviors such as sleep hygiene, parasomnias, nocturnal enuresis, snoring, nocturnal awakening with ingestion of food, daytime sleepiness, and mood, using 29 items graded from one (never) to five (always), giving a final score ranging from 29 to 130 . The higher the SBQ score, the greater the number of sleep problems and consequently the worse the quality of sleep. The instrument was validated for use in Brazil in 2006 ${ }^{14}$.

It was also used the Pediatric QL Inventory (PedsQL ${ }^{\mathrm{TM}}$ 4.0 Generic Core Scales), devised by Varni et al..$^{15}$ with specific versions for children and adolescents validated for use in Brazil by Klatchoian et al. ${ }^{16}$. This consists of a modular instrument designed for measuring or assessing QL of children and adolescents between 2 and 18 years-old. It evaluates dimensions of physical, mental, and social health and the role of school function. This study applied the specific versions of the inventory for each age group of the study population, namely: child report ( from 8 to 12 years-old); and adolescent report (from 13 to 18 years-old), according to the respective instructions for each age group. Psychosocial functioning score was obtained by summing the mean scores for social, emotional, and school functioning.

This research project had been previously approved by the Research Ethics Committee of the Medical School of Universidade Estadual de Campinas (FCM-UNICAMP), Process no 431/2009, in conformance with the requirements of Resolution no 196/96 from the National Board of Health.

\section{Procedures}

Study Group subjects were assessed immediately prior to their scheduled visits to the outpatient clinic for the sake of convenience. Control subjects were contacted by telephone after permission was granted by their school administrators. Following agreement to take part in the study, days and times were arranged on which control subjects were to convene at the school, which was the venue for assessing the Control Group.

\section{Anthropometric assessment}

Weight and height measurements were taken to calculate BMI, using the standard BMI formula of weight in kilos divided by height squared in meters $\left(\mathrm{kg} / \mathrm{height}^{2}\right)^{17}$.

Weight was measured using a digital balance (Inner Scan Body Composition, Tanita) on a scale accurate to the nearest 
$100 \mathrm{~g}$. Height readings were taken to the nearest $0.1 \mathrm{~cm}$ using a metric, nonelastic $1.5 \mathrm{~m}$ measuring tape mounted vertically against a smooth wall with no skirting board and affixed $1 \mathrm{~m}$ above floor level. All parents and/or guardians of the study participants were submitted to an anthropometric assessment. The BMI results were interpreted according to the World Health Organization (WHO) recommendations ${ }^{11}$.

\section{Statistical analysis}

A descriptive statistical analysis of the involved variables was performed in order to characterize the sample. Comparative analysis between eutrophic and obese groups was performed. The $\chi^{2}$ test was used for qualitative variables. Given the non-normal distribution of the quantitative variables, the Mann-Whitney nonparametric test was applied. Statistical tests and plots were used to test normality. A significance level of $5 \%$ was adopted for all statistical analyses. Data were analyzed using the SPSS for Windows, version 16.0, statistical software package.

\section{RESULTS}

The demographic and clinical characteristics of patients and controls are shown in Table 1.

With regard to medication use in the Obese Group, 37.7\% of subjects reported being in use of the following medications at the interview time: six cases of medication for allergic rhinitis, three for depression, three for arterial hypertension, five for thyroid, two for homeopathic medication, and one case

Table 1. Distribution of frequency and mean for demographic and clinical variables of adolescents and their parents.

\begin{tabular}{|c|c|c|c|}
\hline & $\begin{array}{l}\text { Obese } \\
(n=61)\end{array}$ & $\begin{array}{l}\text { Eutrophic } \\
(n=59)\end{array}$ & $p$-value \\
\hline \multicolumn{4}{|l|}{$\begin{array}{l}\text { Demographic variables of } \\
\text { adolescents }\end{array}$} \\
\hline Male & $35(57.4 \%)$ & $26(44.1 \%)$ & 0.02 \\
\hline Female & $26(42.6 \%)$ & $33(55.9 \%)$ & \\
\hline Age (Mean) & $11.9(1.3)$ & $11.7(1.2)$ & 0.76 \\
\hline Body mass index (Mean) & $31.0(5.1)$ & $18.3(2.4)$ & $<0.001 *$ \\
\hline \multicolumn{4}{|l|}{$\begin{array}{l}\text { Demographic variables of } \\
\text { parents }\end{array}$} \\
\hline Age (Mean) & $40.3(7.0)$ & $41.9(9.1)$ & 0.52 \\
\hline Body mass index (Mean) & $30.7(6.8)$ & $25.2(3.9)$ & $0.01 *$ \\
\hline \multicolumn{4}{|l|}{ Economic status } \\
\hline$A$ and $B$ & $21(34.4 \%)$ & $31(52.5 \%)$ & 0.06 \\
\hline C and D & $40(65.6 \%)$ & $28(47.5 \%)$ & \\
\hline \multicolumn{4}{|l|}{$\begin{array}{l}\text { Clinical variables of } \\
\text { adolescents }\end{array}$} \\
\hline School grade repetition & $12(19.7 \%)$ & $3(5.1 \%)$ & $0.02^{\star}$ \\
\hline Health problems & $30(32.8 \%)$ & $4(6.8 \%)$ & $<0.001 *$ \\
\hline Medication use & $23(37.7 \%)$ & $4(6.8)$ & $<0.001 *$ \\
\hline Sleep problems & $19(31.1 \%)$ & $10(16.9 \%)$ & $<0.001 *$ \\
\hline
\end{tabular}

each for diabetes mellitus, hyperactivity, digestive problem, and as an anti-inflammatory.

In the Eutrophic Group, only four cases (6.8\%) reported regularly taking medication, of which two involved homeopathic ones, one for allergic rhinitis while one study participant was in use of ophthalmic solution at the time of the study interview.

Table 2 presents sleep problems through the SBQ.

Finally, the Obese Group had worse QL compared to the Control across all domains, except for school function that did not differ between the groups $(p=0.40)$. (Table 3$)$.

\section{DISCUSSION}

The present study reports the QL status and sleep-related problems of a group of obese adolescents older than 10 years of age. These results can serve as indicators on the need for intervention strategies in lifestyle and habits of this population.

The results of this study evidenced a statistically significant difference in sleep quality between the groups of adolescents, where the Obese Group had a higher frequency of sleep problems and consequently worse sleep quality, compared to the Eutrophic one. Several pediatric studies have confirmed the relationship between sleep and obesity in children and adolescents, showing that insufficient sleep is a risk factor for obesity, with OSAS numbering one of the most important causes ${ }^{18,19}$.

Studies have shown that peaks in growth hormone production occur during sleep. Leptin and ghrelin, hormones involved in controlling satiation and hunger, are also linked to sleep. Therefore, partial chronic sleep loss can increase food consumption and apathy towards physical activity ${ }^{20}$.

Table 2. Questionnaire on sleep behavior assessed by the Sleep Behavior Questionnaire.

\begin{tabular}{llc}
$\begin{array}{l}\text { Obese } \\
\text { Mean / SD }\end{array}$ & $\begin{array}{l}\text { Eutrophic } \\
\text { Mean / SD }\end{array}$ & p-value \\
\hline $51.6(12.3)$ & $47.5(12.8)$ & $0.03^{\star}$ \\
\hline Mann-Whitney's test; ${ }^{*}$ p $<0.05$; SD: standard deviation; &
\end{tabular}

Table 3. Peds quality of life scores on quality of life domains: group $>10$ years-old.

\begin{tabular}{|c|c|c|c|}
\hline $\begin{array}{l}\text { Quality of life } \\
\text { domains }\end{array}$ & $\begin{array}{c}\text { Obese }(n=61) \\
\text { Mean / SD }\end{array}$ & $\begin{array}{c}\text { Eutrophic }(n=59) \\
\text { Mean / SD }\end{array}$ & $p$-value \\
\hline Physical functioning & $67.6(18.2)$ & $82.4(13.6)$ & $<0.001 *$ \\
\hline $\begin{array}{l}\text { Emotional } \\
\text { functioning }\end{array}$ & $60.0(23.0)$ & $68.2(21.6)$ & $0.03 *$ \\
\hline Social functioning & $76.5(22.4)$ & $87.4(16.2)$ & $0.002 *$ \\
\hline School functioning & $71.9(16.4)$ & $73.0(21.2)$ & 0.40 \\
\hline $\begin{array}{l}\text { Psychosocial } \\
\text { functioning }\end{array}$ & $69.5(16.0)$ & $76.2(16.7)$ & $0.009 *$ \\
\hline Overall quality of life & $68.8(15.2)$ & $78.4(14.5)$ & $<0.001 *$ \\
\hline
\end{tabular}


Recently, a study ${ }^{21}$ conducted in Alhambra, California involving 356 fifth-grade students from six public and private schools revealed a significant association between sleep onset latency and emotional eating $(\mathrm{p}=0.30)$, depressive symptoms $(\mathrm{p}<0.0001)$, and anxiety traits $(\mathrm{p}>0.0001)$. These results suggest that sleep onset latency is associated with greater anxiety as well as depressive and emotional symptoms, and that sleep disorders contribute to weight gain and obesity with consequent impairment in the QL.

A study by Crabtree et al. ${ }^{22}$ assessing health-related QL using the PedQL and Child Depression Inventory in obese children with sleep disorders, revealed that children with suspected sleep-disordered breathing, independently of the severity of the index of apneas or presence of obesity, had more compromised QL and depressive symptoms compared to those without apnea.

The prevalence of sleep disorders also evident in the Eutrophic Group is of clinical relevance, since the sample of this study compared severely obese adolescents with healthy adolescents. However, the aim of this study was not to assess or discuss the implications of sleep deprivation in this group, although this finding points to the need for future investigations. Clearly, further studies are warranted to elucidate these issues, in which the presented results represent a limitation in the scope of the present study.

In our group of obese adolescents, a significant relationship was evident between obesity and impaired QL on the PedsQL affecting social, emotional, and psychosocial functioning domains as well as overall QL. The greatest difference identified between the groups was on the psychosocial assessment ( $p=0.009$ ). These results corroborated the findings reported in the study by Luiz et al. ${ }^{2}$, who discussed whether psychological disorders such as anxiety, depression and social adjustment problems represent the cause or the effect in the weight gain process. The emotional domain involves issues related to feelings of fear, anger, sadness, self-concerns, and sleeping difficulties.

In the present evaluation, the physical domain differed in the Obese Group compared to the Eutrophic one $(p=0.001)$, significantly influencing overall QL. The responses to questions on physical domain revealed problems on walking, running, practicing sports, and feeling drained, corroborating evidence in previous studies that increased obesity prevalence is closely linked to changes in lifestyle with reduced physical activity and unhealthy eating habits ${ }^{23}$. Use of medications and number of school grade repeaters was greater in the Obese Group on interview. Nevertheless, no statistically significant difference between the groups was detected for the school function domain on the PedsQL, where school difficulties and not necessarily school grade repetitions are explored under this item.

Schwimmer et al. ${ }^{24}$ compared the severity of obesity using the PedsQL to assess children with cancer and with obesity. These authors reported that the QL among the obese was as poor as that of the gravely ill patients subject to serious hospital interventions, with compromise to activities of daily living as well as social and family life.

Although often unperceived by the family because parents also suffer from overweight (the case in this study), obesity in adolescence often affects self-esteem and sociability, where environmental factors and family eating patterns contribute to obesity ${ }^{25}$. In an effort to improve children's quality of physical and mental health, families must seek to incorporate outdoor interventions and nutritional reeducation. Health programs should be recommended to the adolescents and their families aimed at assessing and modifying lifestyles and providing health education, bearing in mind that parents play an important role in educating the family, providing guidance on food choices and support to practice physical activities and make healthier leisure-time choices.

This scenario illustrates a key question concerning a modern cultural malaise in which children experience abandonment due to the burden of duties born by family members, particularly mothers. Indeed, studies clearly show that negligent child feeding practices contribute to overweight and obesity ${ }^{26}$.

Obesity affects adolescents on all aspects related to their health and QL, making them vulnerable to exclusion through discrimination and social isolation, as well as to problems expressing their feelings. Sleep problems in turn increase the risk for overweight, obesity, and reduced physical activity, and may also lead to lack of attention at school, memory loss, depression, and anguish. Addressing and diagnosing sleep disorders is of prime importance, as it is also elucidating the habits of adolescents and their families, to enable pertinent guidance on sleep hygiene and treatment to be given, thereby preventing severe sleep problems. Moreover, lack of intervention can lead to the persistence of sleep disorders into adult life.

Numerous studies are available on sleep disorders in children and adolescents, QL and obesity; however, few investigations have addressed this triad with the aim of improving development in this pediatric group.

In conclusion, obesity in adolescence is associated with impaired QL and higher frequency of sleep problems. The most affected QL domains in this group were physical, emotional, and social functioning. 


\section{References}

1. Sociedade Brasileira de Pediatria. Obesidade na infância e adolescência: manual de orientação. São Paulo: Sociedade Brasileira de Pediatria, Departamento de Nutrologia; 2008.116 p.

2. Luiz AMG, Gorayeb R, Liberatore Júnior RDR. Avaliação de depressão, problemas de comportamento e competência social em crianças obesas. Est Psicol 2010;27:41-48.

3. Cataneo C, Carvalho AMP, Galindo EMC. Obesidade e Aspectos Psicológicos: maturidade emocional, auto-conceito, locus de controle e ansiedade. Psicol Reflex Crit 2005;18:39-46.

4. Mesquita G, Reimao R. Nightly use of computer by adolescents: its effect on quality of sleep. Arq Neuropsiquiatr 2007;65:428-432.

5. Moreira P, Santos S, Padrão P, et al. Food patterns according to sociodemographics, physical activity, sleeping and obesity in Portuguese children. Int J Environ Res Public Health 2010;7:1121-1138.

6. Rocha CR, Rossini S, Reimão R. Sleep disorders in high school and pre-university students. Arq Neuropsiquiatr 2010;68:903-907.

7. Crispim CA, Zalcman I, Dáttilo M, Padilha HG, Tufik S, Mello MT. Relação entre sono e obesidade: uma revisão de literatura. Arq Bras Endocrinol Metab 2007;51:1041-1049.

8. Chang SJ, Chae KY. Obstructive Sleep Apnea Syndrome in Children: Epidemiology, pathophisiology, diagnosis and sequelae. Korean J Pediatr 2010;53:863-871.

9. Stein MA, Mendelsohn J, Obermeyer WH, Amromin J, Benca R. Sleep and behavior problems in school-aged children. Pediatrics 2001;107:60.

10. Ravens-Sieberer U, Redegeld M, Bullinger M. Quality of life after inpatient rehabilitation in children with obesity. Int J Obes Relat Metab Disord 2001;25(Suppl 1):S63-S65.

11. World Health Organization. Child growth standards: methods and development. Head circumference-for-age, arm circumferencefor-age, triceps skinfold-for-age and subscapular skinfold-for-age. Geneva: World Health Organization; 2007. 217 p.

12. Associação Brasileira de Empresas de Pesquisa (ABEP). Critério de Classificação Econômica Brasil (CCEB) [citado 2 abr 2010]. Disponível em http://www.abep.org/novo/Content. aspx? ContentID=302

13. Cortesi F, Giannotti F, Ottaviano S. Sleep problems and daytime behavior in childhood idiopathic epilepsy. Epilepsia 1999;40:1557-1565.
14. Batista BHB, Nunes ML. Language validation of two scales to evaluate sleep quality in children.J Epilepsy Clin Neurophysiol 2006;12:143-148.

15. Varni JW, Seid M, Rode CA. The PedsQL: measurement model for the pediatric quality of life inventory. Med Care 1999;37:126-139.

16. Klatchoian DA, Len CA, Terreri MT, et al. Quality of life of children and adolescents from São Paulo: reliability and validity of the Brazilian version of the Pediatric Quality of Life Inventory ${ }^{\mathrm{TM}}{ }^{\text {version } 4.0}$ Generic Core Scales. J Pediatr 2008;84:308-315.

17. Sociedade Brasileira de Pediatria. Avaliação nutricional da criança e do adolescente - Manual de Orientação/Sociedade Brasileira de Pediatria. Departamento de Nutrologia. São Paulo: Sociedade Brasileira de Pediatria; 2009. $112 \mathrm{p}$

18. Lytle LA, Pasch KE, Farbakhsh K. The relationship between sleep and weight in a sample of adolescents. Obesity 2011;19:324-331.

19. Carter R 3rd, Watenpaugh DE. Obesity and obstructive sleep apnea: or is it OSA and obesity? Pathophysiology 2008;15:71-77.

20. Verhulst SL, Rooman R, Van Gaal L, De Backer W, Desager K. Is sleepdisordered breathing an additional risk factor for the metabolic in obese children and adolescents? Int J Obes 2009;33:8-13.

21. Nguyen-Rodriguez ST, McClain AD, Spruijt-Metz D. Anxiety mediates the relationship between sleep onset latency and emotional eating in minority children. Eat Behav 2010;11:297-300.

22. Crabtree VM, Varni JW, Gozal D. Health-related quality of life and depressive symptoms in children with suspected sleep-disordered breathing. Sleep 2004;27:1131-1138.

23. Wang Y, Monteiro C, Popkin BM. Trends of obesity and underweight in older children and adolescents in the United States, Brazil, China and Russia. Am J Clin Nutr 2002;75:971-977.

24. Schwimmer JB, Burwinkle TM, Varni JW. Health-related quality of life of severely obese children and adolescents. JAMA 2003;289:1813-1819.

25. Johannsen DL, Johannsen NM, Specker BL. Influence of parents' eating behaviors and child feeding practices on children's weight status. Obesity 2006;14:431-439.

26. Barros Filho AA. A visibilidade da criança ao longo da história. Cienc Saúde Coletiva 2010:15:332-333. 